

\title{
Educación en tiempos de pandemia: tensiones, evidencias y emergencias de la relación educación y tecnología
}

\section{Resumen}

Este artículo hace parte de las discusiones, indagaciones y reflexiones que hemos tenido en el Grupo de Educación en Ambientes Virtuales (EAV) de la Universidad Pontificia Bolivariana de Medellín, en el marco de la pandemia a poco menos de un año del aislamiento preventivo decretado en Colombia el pasado 16 de marzo de 2020. Derivado de este ejercicio presentamos cincos aspectos que representan tensiones, evidencias y emergencias que debemos considerar para enfrentar la nueva cotidianidad educativa. A partir de un contexto sobre algunas de las características de la educación en Colombia, se plantean elementos de la nueva cotidianidad educativa y sus implicaciones; las distintas caras de la brecha digital, que han acentuado nuestras desigualdades; la inminencia de una pedagogía híbrida que invita a asumir nuevas reflexiones pedagógicas; la importancia de crear ambientes no solo para gestionar el aprendizaje sino las emociones, y finalmente una invitación a repensar los límites y oportunidades que nos brinda la tecnología en cada contexto.

Palabras clave: Pandemia. Covid-19. Educación. Brecha digital. Pedagogía híbrida.

\author{
María Elena Giraldo-Ramírez \\ Universidad Pontificia Bolivariana \\ - Medellín - Colombia \\ maria.giraldo@upb.edu.co
}

\section{Gloria María Álvarez Cadavid}

Universidad Pontificia Bolivariana

- Medellín - Colombia

gloria.alvarez@upb.edu.co

\section{Para citar este artigo:}

GIRALDO-RAMÍREZ, María Elena; ALVAREZ-CADAVID, Gloria María. Educación en tiempos de pandemia: tensiones, evidencias y emergencias de la relación educación y tecnología. Revista Linhas. Florianópolis, v. 22, n. 48, p. 122-137, jan./abr. 2021. 
Education in pandemic times: tensions, evidences and emergencies in the relationship between education and technology

\begin{abstract}
This article is part of the discussions, inquiries and reflections that we have had in the Group of Educación en Ambientes Virtuales (EAV) of the Universidad Pontificia Bolivariana, Medellín; in the framework of the pandemic, just less than a year after the decreed of preventive isolation in Colombia on March 16, 2020. Derived from this exercise, we present five aspects that represent tensions, evidences and emergencies that we must consider facing the new educational daily life. From a context on some of the characteristics of education in Colombia, raise elements of the new educational daily life and its implications; the different faces of the digital divide, which have accentuated our inequalities; the imminence of a hybrid pedagogy that invites us to assume new pedagogical reflections; the importance of creating environments not only to manage learning but emotions, and finally an invitation to rethink the limits and opportunities that technology offers us in all contexts.
\end{abstract}

Keywords: Pandemic. Covid-19. Education. Digital divide. Hybrid pedagogy.
Educação em tempos de pandemia: tensões, evidências e emergências na relação entre educação e tecnologia

\section{Resumo}

Este artigo é parte das discussões, indagações e reflexões que tivemos no Grupo de Educación en Ambientes Virtuales (EAV) da Universidad Pontificia Bolivariana, Medellín; no marco da pandemia, pouco menos de um ano após o decreto de isolamento preventivo na Colômbia em 16 de março de 2020. Derivado deste exercício, apresentamos cinco aspectos que representam tensões, evidências e emergências que devemos considerar para enfrentar o novo cotidiano educacional. A partir de um contexto sobre algumas das características da educação na Colômbia, levantar elementos do novo cotidiano educacional e suas implicações; as diferentes faces da exclusão digital, que acentuaram nossas desigualdades; a iminência de uma pedagogia híbrida que nos convida a assumir novas reflexões pedagógicas; a importância de criar ambientes não só para gerir a aprendizagem, mas também as emoções e, por fim, um convite para repensar os limites e oportunidades que a tecnologia nos oferece em todos os contextos.

Palavras-chave: Pandemia. Covid-19. Educação. Exclusão digital. Pedagogia híbrida. 


\section{Introducción}

La situación de la educación en tiempos de la Covid-19 no parece tener una fecha específica de terminación: lo que muchos llaman "nueva normalidad", podría ser una transformación humana a una nueva circunstancia de salubridad y relacionamiento. A este momento de la pandemia ya se puede identificar una progresión en las reacciones y reflexiones sobre su incidencia en el ámbito educativo. Primero, una reacción al paso abrupto del aula física al aula virtual, del campus físico al hogar, del cara a cara presencial a la interfaz de una videollamada o videoconferencia; en suma, a una cotidianidad que transcurre en gran medida en la pantalla.

En nuestro caso, esas primeras ideas estaban acompañadas por una convicción acerca de la necesidad permanente de pensar y establecer cómo nos adaptábamos a esta nueva situación. Como parte de un grupo de investigación con dos décadas dedicadas al estudio de la educación en ambientes virtuales ${ }^{1}$, nunca imaginamos que podríamos vivir una experiencia semejante a la que nos ha enfrentado esta pandemia modelo 2020, producida por la Covid-19. Si bien la humanidad ya había pasado por otras pestes, nuestra época marcada por las grandes posibilidades de las tecnologías digitales le ha dado un sello diferente, al permitir la conectividad y el acceso a la información de manera inmediata. Este escenario es hoy un buen lugar para tratar de responder a las preguntas que, de alguna manera, siempre nos asaltan en la educación, pero que la prisa cotidiana y las rutinas construidas por años las postergan indefinidamente.

En este momento, a un año de haberse decretado la pandemia, si se quiere más atemperados, pero a la vez más cuestionados, centramos nuestra reflexión en cinco aspectos de la educación que consideramos se ven alterados por esta situación inédita y demandan, por tanto, una revisión urgente por parte de los distintos actores educativos para concertar, en lo posible, unas líneas de acción.

Antes de compartir las reflexiones sobre estos cinco aspectos, se hace necesario presentar un breve contexto de la situación de la educación en Colombia, que nos brinda

\footnotetext{
${ }^{1}$ Grupo de Educación en Ambientes Virtuales (EAV) de la Escuela de Educación y Pedagogía de la Universidad Pontificia Bolivariana de Medellín (Colombia).
} 
un marco de interpretación a la lectura que hacemos sobre la educación en tiempos de pandemia. A continuación, presentamos algunos elementos que caracterizan el sistema educativo en Colombia, con el fin de permitir una lectura más ajustada de las reflexiones compartidas en este artículo.

\section{Panorama general de la educación en Colombia}

Colombia ocupa el tercer lugar en Latinoamérica en cuanto al número de habitantes (48 millones) luego de Brasil y México, con un 77,1\% de la población ubicada en centros urbanos (DANE, 2018). Con estas cifras en ciernes, es claro que la mayoría de la población en edad escolar es atendida en las cabeceras municipales y un porcentaje minoritario del $22,9 \%$ en la ruralidad. El sistema educativo colombiano resulta complejo de entender, dada la diversidad de instituciones que participan de este y la estructura descentralizada que tiene. Para explicar un poco lo anterior, habría que advertir que, si bien la constitución de 1991 declaró la educación como un derecho ciudadano, la cual es obligatoria durante 10 años, es decir desde los 5 a los 15 años de edad, en Colombia hay una fuerte participación del sector privado en la prestación del servicio educativo. La manera en que opera en el territorio colombiano es muy dispar:

El sistema educativo colombiano tiene un poco más de estudiantes matriculados en instituciones privadas que el promedio de la OCDE. Las instituciones privadas matriculan el $19 \%$ de los estudiantes de primaria y básica secundaria (el promedio de la OCDE es del 10\% y $14 \%$, respectivamente) y el $23 \%$ de los estudiantes de educación media (el promedio de la OCDE es del 19\%). El número de inscritos en educación privada es particularmente alto en la educación superior: $47 \%$, comparado con el promedio de la OCDE del 30\%. Las estadísticas nacionales indican que Colombia tenía 9.559 sedes escolares privadas de primaria y secundaria, y 51.948 sedes escolares públicas en 2014. En un país con altos índices de pobreza, el alcance de la prestación del servicio por entes privados tiene implicaciones importantes para la equidad en la educación. (OCDE, 2016)

Con este panorama es de esperarse que factores como el acceso, la calidad, la equidad y la permanencia dentro del proceso formativo sean muy variados y, en especial, 
estos aspectos estén en desventaja en las zonas rurales donde no cuentan con las condiciones ni los recursos suficientes para elevar su nivel. Así las cosas, es un hecho que antes de la pandemia ya en Colombia existía una brecha entre la educación pública y privada; la educación rural y la urbana.

\section{Condiciones de la educación en Colombia durante la pandemia}

Dado lo anterior, afirmar que el virus nos ha igualado es, cuando menos, un despropósito. Por supuesto, el virus ataca a la especie humana por igual, pero estamos lejos de que todos los seres humanos tengamos las mismas condiciones sociales, económicas, de salubridad, alimentarias, psíquicas, etc., para hacerle frente. Es decir, las condiciones de vulnerabilidad son diversas y profundas en un país como Colombia, el cuarto más desigual del mundo de acuerdo con el índice de Gini del Banco Mundial (DINERO, 2018). Todas estas vulnerabilidades reflejan los problemas de inequidad que deja a la mayor parte de la población colombiana por fuera de las oportunidades de acceso a derechos fundamentales como la salud, la alimentación y la educación.

Como resultado de la crisis generalizada ocasionada por la pandemia, en Colombia los índices de desarrollo han decrecido. De acuerdo con el Centro de Investigación Económica y Social - Fedesarrollo: “Al país le tomó más de una década recuperar los niveles de desempleo previos a esta crisis económica" (MEJÍA, 2020). Esa recuperación se nota en las cifras del año 2000, cuando la tasa de desempleo era del $20.2 \%$, y en el 2019 del $10.5 \%$. En lo corrido de la pandemia, hasta octubre de 2020, el desempleo había aumentado al $16.6 \%$. Además, el deterioro y el bajo crecimiento económico producto de la pandemia, plantean un escenario de aumento de la pobreza en el país de entre 41,9\% y 43,9\% para 2020 (MEJíA, 2020).

En este contexto, además, es importante conocer los datos de conectividad y acceso que, en las actuales circunstancias de pandemia, resultan indispensables para la continuidad de la escolaridad. Según datos del censo nacional, en 2018 Colombia tenía un $43 \%$ de conectividad en los hogares (GARZÓN, 2020). Este porcentaje está concentrado en 
las ciudades y en los estratos del tres al seis². Otras cifras reveladoras son las que presentó el pedagogo Julián de Zubiría (2020): recientemente en 2018 el 63\% de los bachilleres no tenía acceso a internet desde sus hogares y, en las zonas rurales, tan solo el $9 \%$ de los jóvenes disponían de computador. Esto deja en evidencia que, para un alto porcentaje de trabajadores y estudiantes, el teletrabajo y la educación remota o en línea no es una opción, simple y llanamente, porque no tienen lo básico: un computador y acceso a internet 3 .

\section{¿Una nueva cotidianidad educativa?}

Aludiendo al título de una reciente columna de Jorge Carrión (2020): la biología y no la tecnología, como se esperaría, está acelerando la digitalización del mundo. Ahora bien, este proceso de digitalización acelerado por causas biológicas, en este caso un virus (SARSCoV-2), está teniendo implicaciones profundas en nuestra cotidianidad, en la desaparición de rituales (HAN, 2020) y gestos cotidianos que implican proximidad física e instan a preservar las relaciones sociales, pese al aislamiento. Como lo expresan Rosalía Winocur (2020), el miedo que nos producía antes de la pandemia quedarnos sin conexión a internet, abrió paso a un miedo, impensable, por la desconexión de la presencia física en las relaciones sociales. ¿Cómo afecta esto a la educación, particularmente, a los procesos de enseñanza y aprendizaje?

La situación de aislamiento implica para docentes, estudiantes y padres de familia, reorganizar la vida cotidiana y reubicar la escuela como institución educativa (desde la básica hasta la superior). El aislamiento obligatorio concentró la cotidianidad de la familia y la comunidad en unos pocos metros cuadrados, restringió la movilidad física a unas coordenadas mínimas de espacio y tiempo, dejó en el limbo los trabajos considerados “no

\footnotetext{
${ }^{2}$ En Colombia funciona la estratificación socioeconómica para servicios públicos domiciliarios como una forma de clasificación de los inmuebles, para cobrar de manera diferenciada los servicios públicos de acuerdo con las capacidades económicas. Los estratos se clasifican de la siguiente manera: 1 (Bajo-bajo), 2 (Bajo), 3 (Medio-Bajo), 4 (Medio), 5 (Medio-Alto) y 6 (Alto) (DANE, 2020).

3 Este es uno de los llamados que hace la UNESCO en sus nueve ideas para la acción pública, "ampliar la definición del derecho a la educación para que aborde la importancia de la conectividad y el acceso al conocimiento y la información." (UNESCO; ISAELC, 2020, p. 5).
} 
esenciales" y, con ello, produjo debacles económicas que afectan a familias y a personas concretas. $Y$ en esto es imperativo concentrarnos en este momento.

En términos económicos, los costos de la pérdida del trabajo o la reducción salarial de las cabezas de hogar se suelen ver más fácilmente, por las restricciones para cubrir las necesidades básicas de una vida digna que profundizan aún más las desigualdades; lo que es más difícil de ver son los costos emocionales. Por ejemplo, la transformación de las rutinas de socialización tiene un costo en el equilibrio socioemocional de los estudiantes que la escuela no puede soslayar. Los espacios educativos brindaban la posibilidad de que los estudiantes tuviesen las mismas oportunidades de acceder a sus servicios, desde lo material (computadores, conectividad, bibliotecas, espacios de ocio y entretenimiento, alimentación, etc.) a lo inmaterial, que se fundamenta, básicamente, en las relaciones (entre pares, con profesores y con otro personal profesional de apoyo socio-económico y socio-emocional). Como nos lo recuerda Philippe Meirieu:

[...] la «educación en casa» no es, no puede ser la escuela: porque, precisamente, la escuela es lo que rompe con las desigualdades familiares y sociales, lo que permite acceder a la alteridad, muchas veces dejada de lado o vivida como una agresión en la cápsula familiar, lo que da a todos la posibilidad de acceder a conocimientos «infinitamente compartibles», como decía Fichte, es decir, capaces de hacernos percibir que, a pesar de nuestras diferencias, todos estamos llamados a participar en la construcción de lo común [...]. (MEIRIEU, 2020)

\section{Una brecha digital más profunda y multidimensional}

Lo que los maestros, estudiantes y padres han estado experimentando en los últimos meses no se puede comparar con las formas planeadas y estructuradas de la educación virtual, la cual exige: uno, más tiempos de preparación del profesorado; dos, otras habilidades digitales que no necesariamente tienen los actores educativos antes mencionados; y tres, unas condiciones de conectividad y acceso óptimas.

Las desigualdades implícitas en la educación, se recrudecen con el imperativo de la educación remota basada en tecnologías digitales que ha impuesto la pandemia y el 
aislamiento social. Esta es la primera de diez recomendaciones que hace la UNESCO para enfrentar la Educación en tiempos de Covid-19: "[...] que las soluciones tecnológicas no perjudiquen a quienes ya parten de una situación de desventaja." (UNESCO, 2020, p. 54).

Derivado de ello, donde la virtualidad es, prácticamente, la única opción para continuar con los estudios, hay que hacerse preguntas básicas sobre las condiciones de los estudiantes y los profesores, no solo en términos de competencias digitales, sino en términos de las condiciones de conectividad y acceso. Por ejemplo, en Colombia, como se evidenció en el contexto, hay muchas regiones especialmente de la ruralidad, con precaria conectividad, donde se ha dado un resurgimiento de la educación mediada por sistemas analógicos: radios locales, canales públicos de TV regional, que adelantan propuestas de apoyo al aula, o el envío de material físico de guías y cartillas al estilo de la educación tradicional a distancia.

En lo corrido de la pandemia ya hay investigaciones que ponen en evidencia el peligro de profundización de la desigualdad anunciado por la UNESCO: un estudio realizado en 59 países mostró que solo la mitad de los estudiantes pudo acceder a todo el contenido escolar durante el cierre de las instituciones educativas (REIMERS; SCHLEICHER, 2020)4. Resulta interesante revisar el reciente estudio del Banco Mundial sobre los impactos potenciales de la pandemia Covid-19 en la pobreza del aprendizaje ${ }^{5}$.

De acuerdo con lo anterior, hacemos las siguientes consideraciones para garantizar una educación inclusiva y de calidad en las actuales circunstancias:

a. Tener claridad sobre las condiciones de conectividad y acceso de los estudiantes y las de los propios profesores. Los estudiantes que se inscribieron en un programa presencial no necesariamente tienen un computador, wifi de alta velocidad, una

\footnotetext{
${ }^{4}$ El estudio denominado "Aprendiendo durante la pandemia", fue dirigido por el profesor de la Universidad de Harvard Fernando Reimers y contó con la participación de la OCDE, el Banco Mundial y la Organización Centena. Una versión preliminar del estudio se encuentra en: https://globaled.gse.harvard.edu/files/geii/files/aprendiendo_durante_la_pandemia_v3-21.pdf .

${ }^{5}$ De 720 millones de niños en edad escolar primaria, 382 millones tienen un aprendizaje deficiente, ya sea fuera de la escuela o por debajo del nivel mínimo de competencia en lectura. La Covid-19 podría aumentar ese número en 72 millones adicionales a 454 millones. En un escenario post-Covid-19 de ausencia de remediación y baja efectividad de mitigación de los efectos del cierre de escuelas, las simulaciones muestran que la pobreza en el aprendizaje aumenta del 53 por ciento de los niños en edad escolar primaria al 63 por ciento. (AZEVEDO; SAAVEDRA; ARIAS, 2020).
} 
impresora / escáner / cámara. Es posible que accedan a Internet desde sus celulares, pero que tengan datos limitados. O que, incluso, no tengan acceso a ningún dispositivo tecnológico.

b. Es también probable que los estudiantes y profesores compartan computador, conexión y otras herramientas con otros miembros del hogar.

c. De la misma manera, la coincidencia en horarios lectivos (o laborales) de los distintos miembros de la familia dificulta las posibilidades del acceso a los contenidos escolares. Lo cual exige flexibilización horaria en la educación.

d. Finalmente, otro aspecto son las condiciones de los espacios físicos de los cuales disponen profesores y estudiantes en el hogar, que ahora funcionan como "la escuela-casa", para estar conectados de seis a ocho horas. Sumado, en el mejor de los casos, a los padres que conservan el trabajo y lo hacen desde casa.

Por lo antes dicho, es necesario tener mayor información sobre las condiciones reales de profesores, estudiantes y padres de familia, para planear de una manera más asertiva y empática los procesos de enseñanza y aprendizaje tanto para las zonas urbanas como para las rurales.

\section{Hacia una pedagogía híbrida: pensar más la pedagogía que la tecnología}

La respuesta acelerada a la condición de aislamiento obligatorio implicó los usos de la mediación tecnológica en sus diversos canales, formatos y dispositivos. Lo que vivimos el primer semestre de 2020 se acerca más a una "educación a distancia temporal" o a una “educación remota” o a una "enseñanza remota basada en tecnología”, que a una educación virtual o educación blended (combinación de presencialidad y virtualidad). Y esto es una respuesta esperada por la urgencia de reemplazar lo que ya no era posible: la copresencia física.

Una pedagogía híbrida es más necesaria ahora que nunca: ver al estudiante más allá de la pantalla, ser conscientes de que hay un ser humano al otro lado, preguntarse por sus condiciones personales que permitan reconocer sus límites y posibilidades, el espacio físico 
del que disponen y los recursos tecnológicos, estar atentos a los problemas de privacidad en un mundo digital cada vez más vigilado; todas estas son consideraciones básicas que debemos hacernos para que el aprendizaje sea posible (STOMMEL, 2020). La pedagogía debe estar en el centro de este trabajo. Una pedagogía híbrida que exige, más que reemplazar la copresencia física, transformar las maneras de una copresencia virtual con elementos consustanciales a las múltiples formas de la comunicación virtual. Los rituales de la interacción cambian en el mundo digital.

Por tanto, transformar no es separar, y prejuzgar lo presencial o lo virtual como ambientes de aprendizaje opuestos. Es un mal principio. La presencialidad física y la virtual no se contraponen, sino que se complementan, en tanto la construcción de un ambiente de aprendizaje está dada por la lectura de las situaciones de enseñanza y aprendizaje. En veinte años de investigación del Grupo EAV no hemos encontrado un consenso definitivo e inequívoco de que un ambiente supere al otro; en lo que sí abunda la literatura es en la manera como un ambiente favorece unos asuntos de la enseñanza y el aprendizaje y otros no. Dominar como docentes ambos ambientes debería redundar en la calidad de la enseñanza y el aprendizaje. Lo virtual y presencial no son opuestos o excluyentes, son complementarios y lo serán cada vez más en una realidad que ya es híbrida, pero que en el escenario educativo la estábamos dilatando (o posponiendo).

Hay buenos docentes, hay buenas propuestas didácticas, pero no hay ambientes buenos o malos por sí mismos. Un ambiente de aprendizaje es un sistema complejo de relaciones humanas y técnicas. No es cuestión de abandonar lo que hacíamos, sino de tener apertura ante una nueva situación. Y lo que sí es claro es que esta pandemia ha sido una oportunidad para interrogar nuestra práctica docente, lo que no excluye una revisión de cómo se ha transformado nuestro saber y sus formas de enseñarlo. Los docentes hemos mantenido mucha preocupación por nuestro conocimiento del saber específico y tal vez esto ha desequilibrado nuestras preocupaciones por las formas en que se enseña y aprende ese saber. Hay que retomar esas preguntas esenciales desde lo pedagógico. 


\section{Ambientes de acogida para enseñar y aprender}

Sean Michael Morris, director del Laboratorio de Pedagogía Digital de la Universidad de Colorado plantea que "La idea de poder transferir lo que estás haciendo en un aula a un sitio en línea tiene sus propios problemas. Pero tratar de hacerlo en medio de una pandemia es otro problema." (ano apud KAMENETZ, 2020). En este sentido, los maestros deben tener una buena conciencia de los aspectos sociales, emocionales y afectivos de la educación mediada por la tecnología, y sentirse seguros de su capacidad para responder adecuadamente.

En términos de la gestión pedagógica es importante generar ambientes de acogida, una comunicación más empática y vinculante. Quizás el elemento más angustiante para los profesores en sus prácticas de enseñanza durante la pandemia ha sido la naturaleza emocional: la propia y la de los estudiantes. Esto plantea la necesidad de que los maestros sientan "altos niveles de empatía digital, atención y compasión hacia sus alumnos" (SELWYN, 2020).

Ha sido revelador encontrar en los escritos que reflexionan sobre este tiempo de pandemia dos categorías: consideración y compasión. Y no es para menos, en momentos en los que la incertidumbre es un sentimiento generalizado y profundo que no nos exime de tomar decisiones. Así que la sugerencia es tomar decisiones guiados por la consideración y la compasión, que conjugan entendimiento y sentimiento, razón y emoción. De acuerdo con Karen Armstrong (2011) una persona compasiva en vez de estar motivada por el interés propio, está constantemente orientada a los demás. De muchas maneras estas palabras describen el sentido de la docencia: formar es una acción orientada a los otros.

De acuerdo con lo anterior, es imperativo conocer a los estudiantes. Pareciera que hay más supuestos que evidencias sobre ellos que nos llevan a asumir discursos, como aquel de que no tienen problemas con el manejo tecnológico porque todo el día están con sus dispositivos móviles. Una cosa es usar el celular con fines exclusivos de entretenimiento y comunicación, y otra usar la tecnología como mediadora de los procesos de aprendizaje. Para el caso de las instituciones de educación superior, que se preocupan mucho por 
formar en los saberes específicos y profesionales, pero con poco énfasis en enseñar a aprender, se hace necesario contemplar las transformaciones que se han dado en las rutinas de lectura, escritura y en general en las formas de producción del conocimiento con la mediación tecnológica.

En investigaciones precedentes realizadas en el grupo (ÁNGEL-URIBE, VALLEJOGÓMEZ, ZAMBRANO-ACOSTA, 2015; ZAMBRANO-ACOSTA, VALLEJO-GÓMEZ, ÁNGELURIBE, 2013; PRÉSIGA-CUARTA, RINCÓN- HINCAPIÉ, 2016) hemos podido constatar estrategias y hábitos de estudio propias de esta generación de estudiantes en las cuales hay elementos importantes para potenciar sus procesos de aprendizaje, como también hemos constatado que tienen preconceptos que giran sobre los mismos tópicos en los que se considera de poca calidad a la educación virtual.

\section{Vínculos, interacciones y ritmos de aprendizaje}

Es verdad que no podemos resolver los problemas de conectividad de los estudiantes, pero sí podemos abrir espacios de conexión diversos al espacio formativo. Ser creativos y buscar maneras alternas de gestionar la clase nos implican formas de comunicación diferenciadas con los estudiantes. El mejor ritmo de aprendizaje es el propio, decía María Montesori, y esto exige no solo cambiar de formatos y soportes, sino particularmente, repensar la esencia de la práctica docente. Implicar más al estudiante en este proceso, exige identificar sus formas de comunicación, reconocer otra "ecología comunicativa de medios" y sus condiciones y posibilidades de acceso y uso. Siguiendo las recomendaciones de Morris: "Hacerse accesible" por otros medios (preservando la privacidad) como Facebook, Twitter, correo electrónico, WhatsApp, etc.; y promover que los estudiantes también tengan la oportunidad de conectarse entre ellos. (apud KAMENETZ, 2020).

Esta contingencia de la Covid-19 exige también una visión más realista sobre los límites de la tecnología digital en la educación, como lo dice Neal Selwyn (2020): "una mayor conciencia de los límites de las 'soluciones' digitales". Ya no estamos en la ola del creciente entusiasmo por la educación virtual que caracterizó los primeros años; ahora 
estamos en otro lugar, si se quiere más realista: “Ahora que todos tienen experiencia de primera mano de un cambio masivo al aprendizaje en línea, todos deberíamos ser conscientes de los muchos problemas prácticos que se encuentran detrás de este entusiasmo." (SELWYN, 2020).

\section{Consideraciones de cierre}

En definitiva, continuamos intentando nombrar al gusano que está dejando de ser lo que es en el tránsito para ser algo diferente, sin acertar en un estado estabilizado que se pueda identificar. Como indica Ulrich Beck, podríamos ser víctimas del error de la oruga: cuando se encuentra en plena metamorfosis, esta podría lamentar la pérdida del capullo que la envuelve, porque aún no percibe la mariposa [... ]. (ARTOPOULOS, 2011, p. $\mathrm{XVI})$

Situaciones inéditas como la actual se convierten en detonadores de procesos de apropiación que nos obligan a enfrentar o reaccionar de inmediato, pero que luego de pasado ese momento, nos permite entrar en una fase proactiva en la cual llegan las reflexiones y las decisiones para repensar la educación. En este sentido, habría que pasar de los procesos de capacitación en las herramientas tecnológicas para atender las crisis a los procesos de reflexión para transformar las prácticas.

Será necesario conservar esa mirada crítica para lo que sigue con la educación, dado que se ha afirmado, ya repetidamente, que esta no volverá a ser la misma, y es posible que así sea, la educación cambiará, no solo por el efecto impulsado por la crisis viral, sino por la transformación de las concepciones docentes y discentes acerca del aprendizaje y los efectos que en ello tiene la comunicación, la tecnología y las didácticas orientadas al desarrollo profesional y humano.

Por último, llamamos la atención sobre la paradoja que encierra la Covid-19, como lo señala un reciente estudio del Banco Mundial (AZEVEDO; SAAVEDRA; ARIAS, 2020): una catástrofe, pero también un catalizador potencial para la transformación. No nos permitamos ser víctimas del error de la oruga. 


\section{Referências}

ÁNGEL-URIBE, Isabel Cristina, VALLEJO-GÓMEZ, Mercedes; ZAMBRANO-ACOSTA, Juan. Las TIC en las prácticas de estudio: en la búsqueda de estrategias. Revista Q, Medellín, v. 9, n. 18, p. 1-20, 2015.

ÁNGEL-URIBE, Isabel Cristina. Autonomía de las prácticas de estudio en ambientes virtuales de aprendizaje. Revista Q, Medellín, v. 7, n. 13, p. 1-14, 2012.

ARMSTRONG, Karen. Doce pasos hacia una vida compasiva. Barcelona: Paidós, 2011.

ARTOPOULOS, Alejandro. La sociedad de las cuatro pantallas: una mirada latinoamericana. Madrid: Ariel, 2011.

AZEVEDO, João Pedro; SAAVEDRA, Jaime; ARIAS, Omar. Learning poverty in the time of COVID-19: a crisis within a crisis. Washington, D.C: World Bank Group, dic. 2020. p. 8. Disponible en:

http://documents1.worldbank.org/curated/en/163871606851736436/pdf/Learning-Povertyin-the-Time-of-COVID-19-A-Crisis-Within-a-Crisis.pdf. Acceso en: 18 de dic. 2020.

CARRIÓN, Jorge. La biología está acelerando la digitalización del mundo. The New York Times, New York, 29 mar. 2020. Disponible en:

https://www.nytimes.com/es/2020/03/29/espanol/opinion/coronavirus-revoluciondigital.html. Acceso en: 18 dic. 2020.

DANE - Departamento Administrativo Nacional de Estadística. Estratificación socioeconómica para servicios públicos domiciliarios. DANE: Información para todos. Bogotá, 2018. Disponible en: https://www.dane.gov.co/index.php/servicios-alciudadano/servicios-informacion/estratificacion-socioeconomica. Acceso en: 18 de dic. 2020.

DANE, Departamento Administrativo Nacional de Estadística. Censo Nacional de población y vivienda. Bogotá, 2018. Disponible en: https://www.dane.gov.co/index.php/estadisticas-por-tema/demografia-ypoblacion/censo-nacional-de-poblacion-y-vivenda-2018/donde-estamos. Acceso en: 18 dic. 2020.

DE ZUBIRÍA, Julián. La educación en tiempos de cuarentena. Revista Semana, Bogotá, 2020. Disponible en: https://www.semana.com/opinion/articulo/la-educacion-en-tiemposde-cuarentena-columna-de-julian-de-zubiria/661969. Acceso en: 6 mayo 2020.

DINERO. Los 10 países más ricos del mundo... y los 10 más desiguales. Revista Dinero, Bogotá, 2018. Disponible en: http://www.dinero.com/economia/articulo/los-10-paises-masricos-del-mundo-y-los-paises-mas-desiguales/259786. Acceso en: 18 dic. 2020.

GARZÓN, Camilo Andrés. Hay una Colombia para la cual internet no es una alternativa frente al coronavirus. La Silla Vacía, Bogotá, n. 24, 2020. Disponible en: 
https://lasillavacia.com/hay-colombia-cual-internet-no-alternativa-frente-al-coronavirus75959. Acceso en: 18 dic. 2020.

HAN, Byung-Chul. La desaparición de los rituales. Una topología del presente. Barcelona: Herder, 2020.

KAMENETZ, Anya. "Panic-Gogy": teaching online classes during the coronavirus pandemic. National Public Radio (NPR-ORG). Washington, D.C, 2020. Disponible en: https://www.npr.org/2020/03/19/817885991/panic-gogy-teaching-online-classes-duringthe-coronavirus-pandemic. Acceso en: 18 dic. 2020.

MEIRIEU, Philippe. La escuela después ... ¿con la pedagogía de antes? MCEP. Valencia, 2020. Disponible en: http://www.mcep.es/2020/04/18/la-escuela-despues-con-lapedagogia-de-antes-philippe-meirieu/. Acceso en: 18 dic. 2020.

MEJÍA, Luis Fernando. La economía ante el COVID-19: Perspectivas y retos [Seminario Virtual]. La economía y el mercado laboral después del coronavirus. Bogotá, Colombia. 2020. Disponible en: https://www.anif.com.co/evento/seminario-virtual-la-economia-y-elmercado-laboral-despues-del-coronavirus. Acceso en: 18 dic. 2020.

OCDE. Revisión de políticas nacionales de educación. Educación en Colombia. Paris: Publicaciones de la OCDE, 2016. Disponible en: https://doi.org/10.1787/9789264250604-en. Acceso en: 18 dic. 2020.

PRÉSIGA CUARTAS, Karen; RINCÓN HINCAPIÉ, Yesenia. Hábitos de estudio y dispositivos tecnológicos en estudiantes de la Licenciatura en inglés - español en modalidad presencial de la Universidad Pontificia Bolivariana. Universidad Pontificia Bolivariana: Medellín, 2016.

REIMERS, Fernando M.; SCHLEICHER, Andreas. Aprendiendo durante la Pandemia: de la disrupción a la innovación. Paris: OECD, 2020. Disponible en: http://educalidad.com/eventos/aprendiendo-durante-la-pandemia-de-la-disrupcion-a-lainnovacion/. Acceso en: 18 dic. 2020.

SELWYN, Neil. Op-Ed: online learning: rethinking teachers' 'digital competence' in light of COVID-19. SchoolNews. Sydney, 2020. Disponible en: https://www.schoolnews.com.au/news/op-ed-online-learning-rethinking-teachers-digital-competence-in-lightof-covid-19/. Acceso en: 18 dic. 2020.

STOMMEL, Jesse. An open letter on the future of hybrid pedagogy. Hybrid Pedagogy, Denver, 2020. Disponible en: https://hybridpedagogy.org/an-open-letter-on-the-future-ofhybrid-pedagogy/. Acceso en: 18 dic. 2020.

UNESCO; IESALC. COVID-19 y educación superior: de los efectos inmediatos al día después. Análisis de impactos, respuestas políticas y recomendaciones. Caracas, 2020. Disponible en: https://www.iesalc.unesco.org/2020/04/14/iesalc-insta-a-los-estados-a- 
asegurar-el-derecho-a-la-educacion-superior-en-igualdad-de-oportunidades-ante-el-covid19/. Acceso en: 18 dic. 2020.

WINOCUR, Rosalía. La pandemia instaló una nueva experiencia global. Technos Magazine Digital, Buenos Aires, 2020. Disponible en:

http://technosmagazine.com.ar/8conversa.html. Acceso en: 18 dic. 2020.

Recebido em: 14/01/2021 Aprovado em: 20/03/2021

Universidade do Estado de Santa Catarina - UDESC Programa de Pós-Graduação em Educação - PPGE

Revista Linhas

Volume 22 - Número 48 - Ano 2021

revistalinhas@gmail.com 